\title{
Janene Carey
}

\section{Whose story is it, anyway? Ethics and interpretive authority in biographical creative nonfiction}

\begin{abstract}
When a creative nonfiction story is crafted from someone else's lived experience, striking a balance between the interpretive authority of the writer and the ethical treatment of the subject can be problematic. This paper argues that waving the usual flags about informed consent, confidentiality and anonymity is an ineffectual way of dealing with potential threats to an interviewee's privacy, reputation and sense of self. The ethical quandaries that can arise when using lives as material for writing are discussed in the context of my own attempt to take a non-exploitative, non-maleficent, collaborative approach to the task of producing non-superficial, non-rose-tinted, nuanced accounts of home-based palliative caregiving.
\end{abstract}

The tensions involved in telling a story about someone else's life in a way that does not hurt, exploit or misrepresent them, and telling it in a way that preserves your integrity as the writer, have exercised me since I began writing biographically-oriented creative nonfiction. I came to doctoral work in the creative arts from a background of qualitative social science research and so was aware that the principles governing the treatment of research participants in universities - respecting their autonomy, seeking their informed consent, protecting their privacy - can be far easier to espouse than to implement, particularly when the research involves in-depth description and interpretation of lived experience. This paper highlights certain ethical quandaries that can arise when 'using lives' as material for writing; discusses the considerations that have shaped the conduct of my work on home-based palliative caregiving; and explains how a more collaborative process than I originally envisaged has emerged in my creative nonfiction writing practice.

\section{Using lives as fodder for writing}

In the context of university research, life writing has been described as 'the field of Creative Arts study and practice that currently offers most difficulty for the marriage of ethics procedures and creative endeavour' (Evans 2005). Life writing is an umbrella term extending beyond autobiography, biography and 
memoir to embrace writing that draws upon narratives of lived experience across multiple fields, including history, anthropology, psychology, medicine, literary studies and journalism (Eakin 2004). The discussion that follows focuses on a subset of life writing: the situation where one person, the writer, produces an account of the life experience of another person, the subject, and the second person cooperates by being interviewed or providing access to documents. To narrow the focus further, the discussion includes only accounts in which the identities of writer and subject remain distinct, not the case where they artificially collapse into one by means of first person narration, as in the ethnographic or ghostwritten forms of 'collaborative autobiography' considered by Paul John Eakin (1999) and G Thomas Couser (2001). Having established myself at the biographical end of the life writing continuum, I will begin by looking at how various academic and professional writers have grappled with the issue raised with such icy sarcasm by bell hooks: whose voice is allowed to speak in the final text?

Some narrative research has description as its primary goal, and confines itself to a faithful rendition of participants' life experiences from an emic, or insider, point of view. However, many other kinds of researchers take life stories, filter them through a theoretical framework, and use them to shed light on general cultural processes or phenomena (Chase 1996; Richards \& Schwartz 2002). Participants may be shocked to find that what they have told the researcher has been interpreted in a way that is alien to their own conceptions about their identity and the meaning they attach to their experiences. A thought-provoking example of this can be found in Katherine Borland's article "'That's not what I said": Interpretive conflict in oral narrative research' (2006), in which she describes how unimpressed her grandmother was to find her anecdote about a day at the races had been recast as an illustration of female struggle for autonomy within patriarchal structures. In her analysis of this incident, Borland does not advocate what she calls the 'unsatisfactory if not illusory solution' of refraining from interpretation and simply 'letting the subjects speak for themselves' (Borland 2006: 311), as she believes that part of her scholarly role is to create more textured meanings. Instead, she suggests that talking with participants about interpretation can avoid the assumption of commonality where difference exists:

I am suggesting that we might open up the exchange of ideas so that we do not simply gather data on others to fit our own paradigms once we are safely ensconced in our university libraries ready to do interpretation. By extending the conversation we initiate while collecting oral narratives to the later stage of interpretation, we might more sensitively negotiate issues of interpretive authority in our research. (Borland 2006: 319)

The written research product is usually oriented to an academic audience and may incorporate an analysis of participants' attitudes or actions that is not entirely flattering. This can leave the researcher feeling discomfited by the prospect of it being read by the original source. Ruthellen Josselson describes the dread of being confronted with 'How could you say that about me?' and the ambivalence she feels in switching her allegiance from participant to reader: 'Where in the interview I had been responsive to them, now I am using their lives in the service of something else, for my own purposes, to show something to others. I am guilty about being an intruder and then, to some extent, a betrayer' (Josselson 1996a: 69-70). She recognises this as the same kind of betrayal that Janet Malcolm says is practiced upon the journalistic subject where the interviewer who seemed so sympathetic, so keen to understand, only ever intended to write a story of his or her own (Malcolm 1990). 
Even a researcher attracted to the feminist ideal of collaborative research methods might decide to exercise unilateral control over the interpretive process. In writing her book, Ambiguous Empowerment: The work narratives of women school superintendents (1996), Susan Chase decided for pragmatic reasons not to share her interpretations with participants prior to publication. She felt that she was 'racing against the tenure clock' and could not afford time for consultation and negotiation, nor could she afford the risk of losing an entire chapter if one of the four women whose narratives she had extensively analysed withdrew her contribution. She notes:

I felt I had adequately fulfilled my ethical responsibility to participants by sending them their interview transcripts and asking for permission to use specific passages. I had already done more than most social scientists who usually stop at obtaining signatures on informed consent forms (Chase 1996: 49)

Revisiting the decision later, Chase argues that her analysis of the discursive, narrative and linguistic processes embedded in the stories would not have been clarified or validated by participant feedback. She recognises the divergence between her communicative agenda and what the women themselves wanted to express in talking about their experiences, but hopes that her research served their interests 'in a deeper sense', by illuminating how stories of accomplishment and discrimination act to preserve or disrupt individualistic, gender- and race-neutral assumptions in discussions about professional work. In her concluding thoughts, Chase suggests that informed consent forms be tailored to the processes of specific narrative projects and carry an open acknowledgement that even if participants are offered some form of ongoing negotiation over the use of their stories, 'in the end, we claim authority over the interpretive process' (Chase 1996: 57).

In contrast to the angst about appropriating lives voiced by social scientists, biographers tend to wear their interpretive independence as a badge of honour. Janet Malcolm (1995) famously likens them to burglars: peeping through keyholes, rifling through drawers, triumphantly bearing away their loot of dark family secrets and never-before-told anecdotes. In the situation where the subject or family propose to cooperate with the enterprise of turning their life into a narrative, the metaphor she employs is that of the Great White Hunter. The friendly tribe trade their memories for a memorialising account, but they must not assume that their view of what it all means will prevail. Like an explorer appropriating the territory by exercising naming rights, the biographer stakes his or her claim to the dominant authorial voice. To behave otherwise is to run the risk of being unduly influenced by the natives and ending up with a worthless hagiography. However, some biographers become so disenchanted by the nature of their work that they give it up altogether; Cassandra Pybus being one such example (Lindemann 2007). In her article, 'Dogs in the Graveyard' (2000), Pybus describes the 'disconcerting and disagreeable dilemma' of believing writers have an ethical responsibility to consider how their work may expose or hurt living people while also feeling ethically bound to write what she sees as an honest and complete account:

my writerly integrity is bound up in the veracity of the tale I am able to construct out of the vagaries of memory and the treacherous detritus left behind. Since we can never know the truth, it is fundamentally important that what I write makes psychological and moral sense of the material available to me and that my story does say something meaningful about the human condition. (Pybus 2000) 
Like biographers, creative nonfiction writers prize their interpretive independence and take a strong stance on the issue of writerly integrity. Although creative nonfiction is billed as 'the literature of reality' and seeks to be scrupulously accurate in its presentation of information, detached objectivity and impartial coverage of opposing views are not part of its mission. One of the characteristics distinguishing creative nonfiction from conventional journalism is that writing subjectively is 'not only permitted but encouraged' (Gutkind 1997: 15). Creative nonfiction is animated by a personal voice; explicitly or implicitly there is always an 'I', a lively intelligence behind the words, making sense of the subject (Perl \& Schwartz 2006). In 'Living to Tell the Tale: The Complicated Ethics of Creative Nonfiction', Lynn Bloom writes approvingly of the 'implacable I' and declares that 'writers of creative nonfiction live - and die by a single ethical standard, to render faithfully, as Joan Didion says in "On Keeping a Notebook", how it felt to me, their understanding of both the literal and the larger Truth' (Bloom 2003: 278).

Given this valorisation of a personal point of view in creative nonfiction, it is probably not very surprising that when ethics are discussed, the rights of the author in the artistic expression of his or her account, and the rights of the reader in reception of it, receive more vociferous proclamation than subject's rights. As Steve Evans (2005) attests, ethics chapters in creative nonfiction textbooks tend to dwell on issues such as 'faithfulness to truth and the rights of the reader not to be fooled' rather than addressing the proper treatment of human research subjects. Relative allocation of space provides a crude but significant indication of perceived importance: in discussing implicit covenants about accuracy and candour, Mark Kramer devotes two pages to 'The Writer's Relationship to Readers', compared to one page for 'The Writer's Relationship to Sources' (Kramer 1995: 23-26). Lynn Bloom notes that much of the advice about how to write ethical creative nonfiction is couched in legal rather than moral terms: the focus is on 'prudence and jurisprudence' (2003: 278), or how to avoid being sued by the people you write about.

It is tempting to think that when research based on lived experience is done under the aegis of a university, with scrutiny of the protocol by a Human Research Ethics Committee (HREC), participants can be assured of appropriate levels of respect and protection. However, the guidelines that HRECs enforce have their origins in health and medical research and are oriented towards quantitative scientific methods like experiments and surveys (Richards \& Schwartz 2002). The revised Australian National Statement on Ethical Conduct in Research Involving Humans (National Health and Medical Research Council 2007) was notable in that it included, for the first time, some discussion of qualitative research. However, the guidelines provided are far from comprehensive, leaving much to the discretion of the individual researcher.

For instance, the ethical quandaries of life story research, which arise from the risk that the textual representation may threaten the subject's privacy, reputation or sense of self, cannot be simply addressed by means of measures related to informed consent, confidentiality and anonymity. Firstly, providing a clear explanation of the nature of the study and estimating the risks to participants is difficult in such cases, as the research focus is more likely to be emergent than predetermined. In this situation, locating informed consent before data collection begins, and requesting upfront agreement to publications based on that data, is an ethically problematical practice (Richards \& Schwartz 2002), given that the participants 'can, at the outset, have only the vaguest idea of what they might be consenting to' (Josselson 1996b: xii). Also, the privacy of personal information is almost impossible to guarantee when the material being gathered is richly descriptive and the aim is to present it in its proper context rather than stripping it of all identifying features. The inescapable conclusion is 
that researchers working with life stories have to exercise considerable ethical judgment. As Josselson points out, 'There are no easy answers to these questions. Merely waving flags about confidentiality and anonymity is a superficial, unthoughtful response' (1996b: xii).

\section{Writing about home-based palliative caregiving}

I am researching and writing about the experiences of people caring for their loved ones at home during the final stages of a terminal illness. In 2006, I helped nurse my mother when she was bedridden with advanced breast cancer. I found the role of carer quite overwhelming: physically, emotionally and psychologically. Writing about what I was going through, often in the middle of the night, was part of how I coped. After it was all over, I decided to investigate what it was like for other people, and to write up their stories, and mine, as creative nonfiction. My initial intention was to ask palliative care nurses who conduct home visits to help me recruit current carers for a longitudinal study based on reflective journals and a series of interviews. After carefully designing the protocol to take account of the ethical issues that can arise when you are dealing with a vulnerable population and a sensitive topic (see Carey 2008), I received approval from both Hunter New England Health and my university. I later broadened the scope of the research to include past carers, because it proved difficult to locate and retain carers who were able or willing to be involved while they were in the midst of such a taxing time.

So far, all the people I have written about have been ex-carers. The project has shifted to a more retrospective and biographical form, with greater emphasis on characters and relationships than I originally envisaged. However, its conduct continues to be shaped by the initial focus on current carers and the scrupulous attention to ethical conduct involved in making that application to Hunter New England Health. For instance, as palliative care research needs to be particularly sensitive to the possibility that participants might wish to renegotiate their involvement, given the volatile nature of their feelings and circumstances, I opted to employ what is known as process consent, which 'allows consent to be renegotiated at different stages of the interaction between the researcher and the participant' (Beaver, Luker \& Woods 1999). In addition to this, I decided to defer the consent-to-publish permission until I had a working draft. I felt uncomfortable with the idea of asking someone to agree in advance that I could publish what I wrote about them, when neither of us really knew how I would convert their material into a story.

I also had scruples about promising anonymity. I knew the writing, as creative nonfiction, would need to be vivid and specific and, therefore, rich in potentially identifying detail. This meant that people who knew the family being written about would probably recognise them, even if names and places were changed. Besides, I wanted to give participants the option of having their real names appear in publications. Other researchers working with narratives about illness and death have found many participants do not wish to be represented by false names - they want to 'give voice' to their personal experience, and have that voice heard. If they are talking about someone who has died, they may see the published account as a kind of lasting memorial (Grinyer 2004).

As I was admitting in my HREC application that people might be identifiable in publications arising from the research, Hunter New England Health required that participants sight the intended use of their data and sign a Release Form 
prior to publication (Hunter New England NSW Health 2005). Therefore my Information Statement for Participants contained the following message:

The descriptive and detailed nature of the stories I will be writing make it difficult to promise that participants will be anonymous. I can disguise names, dates and locations, but cannot guarantee that someone who knows your family circumstances will not be able to recognise you in the stories.

I will use your information in the book manuscript and thesis for my $\mathrm{PhD}$, for conference papers and for articles in scholarly journals. Prior to submission of the $\mathrm{PhD}$, you will be offered drafts of writing based on your material and showing its usage in context. You will be invited to suggest modifications or request deletions before signing a Release form. If a mutually satisfactory version of the writing cannot be negotiated, you will be completely free to withdraw your contribution. If you want real names to appear with your material in the publication you will have to nominate this option on the Release form, otherwise pseudonyms will be used.

This was compatible with how I wanted to conduct the project; however handing the power of veto so explicitly to participants gave me a frisson of fear. Were those Release Forms a threat to my writerly integrity? Would enforced negotiations about the content of the stories mean that they would all turn out to be sentimental portrayals of courageous patients tended by devoted and self-sacrificing family carers?

Fortunately this has not proved to be the case, despite the fact that my working processes have ended up being very collaborative. I do not just take a finished story back to the respective participant and negotiate changes at that point. Instead, we are involved in an iterative cycle of interviews, with each one incorporating the participant's feedback about how my current draft is shaping up as well as introducing new material that revises, extends, and deepens what I have written so far. Participants get to see what I am doing with their information at an early stage so they find they can trust me not to judge or criticise them. The richness of what they are telling me is progressively enhanced, as is my understanding of its nuances and complexities. For these reasons, I think the ongoing consultation and negotiation makes the stories infinitely better. I also suspect that collaboration at the rough draft stage promotes useful feedback; and that participants who are only asked to comment on a very polished final version may perceive the text as immutable, less open to revision.

Nonetheless, I did not plan this way of working, and have never particularly liked sharing drafts of my writing. It began when one of my participants was on the verge of dropping out and the only thing I could think of doing was to show her what I had written based on our first interview. The story was sketchy and had lots of gaps in it, but reading it persuaded her to stay with the project. I had heard about this particular woman via a mutual acquaintance. I had been given the impression that her sick husband had been a tyrant, allowing no one in the house to nurse him but his wife, who had been run ragged caring for him in the six months before he died. At our first meeting it soon became clear that my interviewee had not regarded her husband as a tyrant. Her rationale for his behaviour was enlightening and convincing. I went home and composed a first draft of the story, writing it in a way that respected her understanding of his personality and her perspective on what their relationship had been like.[1] Thus, I had something to show her when she telephoned to say that she wanted 
to drop out because her adult children were not happy about how she might be exposing their father to public scrutiny. She seemed to feel some remorse about letting me down but obviously family harmony was more important to her. I suggested that she look at the rough version of the story that I had written before she made a final decision and she agreed to do that.

When I contacted her a few days later, she said she was thrilled by the story. She said that she thought it was 'brilliant' and had managed to persuade her children that involvement in my project was not going to result in the besmirching of their father's reputation. Ironically, although it was the sympathetic first draft that averted the threatened withdrawal from the study, in the second interview I was told that the family felt my depiction of this man was not quite right. The message - now that they trusted me - was that I needed to use a few more dark colours in my portrait of him.[2]

It is important to note that despite the consultation that is occurring throughout the writing process, the stories do not speak with the 'cloven tongue' of collaborative autobiography, where the narrator takes on the persona of the subject and tries to ghost-write their thoughts and feelings (Couser 2001). Rather than a negotiated first-person voice telling each story, there are multiple, distinctive voices. The experience of the main character, the primary caregiver, is related through a mixture of quoted speech directed at me as the listening presence, and via passages of summary and explanation narrated in the third person. I appear in each story in the first person, setting the scene and making the occasional comment, and of course I am the voice behind the narrator. This is not unusual in creative nonfiction: the difference is that my presence is minimal and the spotlight is on the person talking to me.

Lee Gutkind did something similar in his story about a woman whose husband made a barter arrangement with the local dentist to have all her teeth pulled out and replaced with false ones, even though her own were perfectly healthy. It appears in the anthology Connecting and is prefaced by these editorial remarks, also written by Gutkind:

The creative nonfiction genre permits - even encourages - the writer's voice, point of view, and involvement. But essays don't require a writer's active presence and, in fact, can be weakened by it. The unique quality of this essay is that the writer has recognized and embraced a character with a story and established himself as a willing listener, waiting for the story to be told. From beginning to end, the reader hears the protagonist's voice - but visualizes the action through the subtle filter of the writer's perceptions and interpretations. (Gutkind 1998: 211)

To craft a story about someone else's experiences, to shape a jumbled assortment of recollections and anecdotes into something readable, inevitably requires exercising the 'subtle filter' referred to by Gutkind. Although this interpretive filter may be unavoidable, I believe it is possible to mitigate its effects, to some extent, by giving subjects a say about how their lives appear in print. Furthermore, such negotiations can enhance rather than diminish the text. Peter Read speaks positively about the intensive feedback he received from Aboriginal activist and senior public servant Charles Perkins on the final draft of his biography, concluding that it enlarged his understanding of a man he had just spent three years studying and resulted in the text becoming more subtle and multi-layered than it had been previously (Read 1992). Perkins made numerous comments, suggestions and corrections in the margins of the draft 
manuscript, which the pair worked through together, page by page, amicably and fruitfully:

Contrary to what one might have expected, the process at no time was one of brow-beating or arguments over author's versus subject's rights. The sessions were co-operative and unexpectedly creative, as our interviews had been (Read 1992: 159).

The effect of the changes was to introduce subtle inconsistencies in Perkins's stated attitudes to certain key events and people; to disrupt the presentation of singular, coherent meanings that Read, as biographer, had unconsciously sought to distil. The eleventh-hour additions reflect, argues Read, 'unresolvable, multivariant interpretations' co-existing in Perkins's mind. Abstaining from an artificial synthesis and allowing the reader to comprehend the biographical subject from reports of their words and actions is 'a methodology sympathetic to the subject's own self-perceptions' and is congruent with how people develop an intuitive understanding of others in everyday life (Read 1992: 169-70).

\section{Conclusion}

Like Peter Read, I have found collaborating on a draft manuscript with the person being written about can be an unexpectedly creative process, and one that promotes a more nuanced understanding. I must admit, however, that the nature of my stories - with information coming principally from one source, involving a testimonial about felt experience and pertaining to sensitive emotional territory - is one where the process of negotiation is eased by the sheer inappropriateness of taking a sceptical or critical approach. Some researchers who use lives as material do need to go beyond the participant's point of view in exercising interpretive authority as scholar or writer. The question of how they can manage this in a way that is ethically defensible is very intriguing. I am fortunate that collaborative methods serve to both enhance my writerly integrity and minimise the risk of hurting, exploiting or misrepresenting people who have agreed to talk with me about a very difficult period of their lives.

\section{Endnotes}

1. As one reviewer commented, the fact that my information about the character and life of the person who has died has been filtered through the living raises additional complex issues of interpretive authority. return to text

2. I would like to thank the reviewer who suggested that more information on actual negotiation processes and outcomes in this project would be interesting, As a result of this comment, I intend to explore this in a future article, when I have completed more work on the project. return to text

\section{List of works cited}

Beaver, K, K Luker \& S Woods 1999 'Conducting research with the terminally ill: challenges and considerations', International journal of palliative nursing 5.1: 13-17 return to text 
Borland, K 2006 "'That's not what I said": interpretive conflict in oral narrative research', in R Perks and A Thomson (eds), The oral history reader, Oxford: Routledge, 310-21 return to text

Carey, J 2008 'Gatekeepers, process consent and real names: ethical aspects of writing vivid stories based on qualitative research in palliative care', Proceedings of the 2 nd annual postgraduate research conference - bridging the gap between ideas and doing research, University of New England, Armidale, 18-26 return to text

Chase, SE 1996 'Personal vulnerability and interpretive authority in narrative research', in R Josselson (ed), Ethics and process in the narrative study of lives vol 4, Thousand Oaks, California: Sage, $45-59$ return to text

Couser, GT 2001 'Making, taking, and faking lives: ethical problems in collaborative life writing', in TF Davis and K Womack (eds), Mapping the ethical turn: a reader in ethics, culture, and literary theory, Charlottesville: University of Virginia Press, 209-26 return to text

Eakin, PJ 1999 How our lives become stories: making selves, Ithaca, NY: Cornell University Press return to text

Eakin, PJ (ed) 2004 The ethics of life writing, New York: Cornell University Press return to text

Evans, S 2005 'Human interest story: ethics and human research in the arts'. Paper presented at the Ethics in Human Research conference, Canberra, May

http://www.nhmrc.gov.au/news/events/_files/evans.pdf (accessed 2 May 2008) return to text

Grinyer, A 2004 'The narrative correspondence method: what a follow-up study can tell us about the longer term effect on participants in emotionally demanding research', Qualitative health research 14.10: 1326 return to text

Gutkind, L 1997 The art of creative nonfiction: writing and selling the literature of reality, New York: John Wiley \& Sons return to text

Gutkind, L 1998 'Teeth', in L Gutkind (ed), Connecting: twenty prominent authors write about the relationships that shape our lives, New York: Penguin Putnam, 211-21 return to text

hooks, b 1990 'Marginality as site of resistance', in R Ferguson, M Gever, TT Minh-ha and C West (eds), Out there: marginalization and contemporary cultures, Cambridge, MA: MIT Press, 341-43 return to text

Hunter New England NSW Health 2005 'Guidelines: initial application for ethics approval for research involving humans', http://www.hnehealth.nsw.gov.au/Human_Research_Ethics/human_research_ethics _committee_application_forms (accessed 11 May 2007) return to text

Josselson, R 1996a 'On writing other people's lives: self analytic reflections of a narrative researcher' in R Josselson (ed), Ethics and process in the narrative study of lives vol 4, Thousand Oaks, California: Sage, 60-71 return to text

Josselson, R (ed) 1996b Ethics and process in the narrative study of lives vol 4, Thousand Oaks, California: Sage return to text

Kramer, M 1995 'Breakable rules for literary journalists', in N Sims and M Kramer (eds), Literary journalism: a new collection of the best American nonfiction, New York: Random House, 21-34 return to text

Lindemann, S 2007 'The writer-subject relationship in collaborative life writing'. Paper presented at the Using Lives postgraduate workshop in biography, Canberra, September return to text

Malcolm, J 1990 The journalist and the murderer, New York: Knopf return to text

Malcolm, J 1995 The silent woman: Sylvia Plath and Ted Hughes, New York: Vintage Books return to text

National Health and Medical Research Council 2007 'National statement on ethical conduct in research involving humans', http://www.nhmrc.gov.au/publications/synopses/_files/e72.pdf 
(accessed 19 April 2007) return to text

Perl, S \& M Schwartz 2006 Writing true: the art and craft of creative nonfiction, York: Houghton Mifflin return to text

Pybus, C 2000 'Dogs in the graveyard', Australian Humanities Review,

http://www.australianhumanitiesreview.org/archive/Issue-December-1999/pybus 1.html (accessed 27 February 2008) return to text

Read, P 1992 'A phantom at my shoulder: the final draft of Charles Perkins: a biography', in I Donaldson, P Read and J Walters (eds), Shaping lives: reflections on biography, Canberra: The Humanities Research Centre, ANU, 155-70 return to text

Richards, HM \& LJ Schwartz 2002 'Ethics of qualitative research: are there special issues for health services research?' Family Practice 19.2: 135-39 return to text

\section{Acknowledgments}

An earlier and considerably briefer version of this paper was presented at The Art of The Real: National Creative Non-Fiction Conference, May 16-18, 2008, University of Newcastle, Australia.

Janene Carey has a BA from the University of Sydney in philosophy and computer science and spent many years as an IT professional. Her Master of Economics from UNE involved interpretive case studies of role negotiations between small business owners and consultant web developers, and was preceded by a research methods unit which she later helped to teach. She is currently completing a PhD in creative writing on the topic of home-based palliative caregiving.

\section{TEXT}

Vol 12 No 2 October 2008

http://www.textjournal.com.au

Editors: Nigel Krauth \& Jen Webb

Text@griffith.edu.au 